\title{
Estratégia\&Negócios
}

ISSN 1984-3372

http://www.portaldeperiodicos.unisul.br/index.php/EeN/

\section{GESTÃO DE PROJETOS APLICADA AOS CONTRATOS DE NOVOS PRODUTOS NO SETOR DE AUTOPEÇAS}

\section{PROJECT MANAGEMENT APPLIED TO CONTRACTS OF NEW PRODUCTS IN THE AUTOMOTIVE SECTOR}

\section{Rudolf Friedrich Fromm}

Faculdade FIA de Administração e Negócios. MBA Executivo Internacional - FIA.

E-mail: rudolf.fromm@gmail.com

\section{Emerson Antonio Maccari}

Doutor em Administração pelo Programa de Pós-Graduação em Administração - PPGA/FEA USP com Estágio doutoral na University of Massachusetts Amherst - USA. Professor do Mestrado Profissional em Administração: Gestão de Projetos, Universidade Nove de Julho - Uninove, São Paulo, Brasil.

E-mail: emersonmaccari@gmail.com

\section{Cláudia Terezinha Kniess}

. Professora do Programa de Mestrado Profissional em Administração - Gestão de Projetos - PMPA-GP. Universidade Nove de Julho

E-mail: kniesscl@yahoo.com.br

\section{Cesar Augusto Biancolino}

Professor do Programa de Mestrado Profissional em Administração - Gestão de Projetos - PMPA-GP. Universidade Nove de Julho.

E-mail: biancolino@gmail.com

\section{Giovane da Costa}

Mestrando do Programa de Pós-Graduação em Administração - Universidade Nove de Julho.

E-mail: giovanedc@gmail.com

Recebido em 25/09/2011. Aprovado em 14/11/2011. Disponibilizado em 03/12/2011.

Avaliado pelo Sistema double blind review

R. eletr. estrat. neg., Florianópolis, v.4, n.2, p. 87-116, jun./dez. 2011

http://portaldeperiodicos.unisul.br/index.php/EeN/index
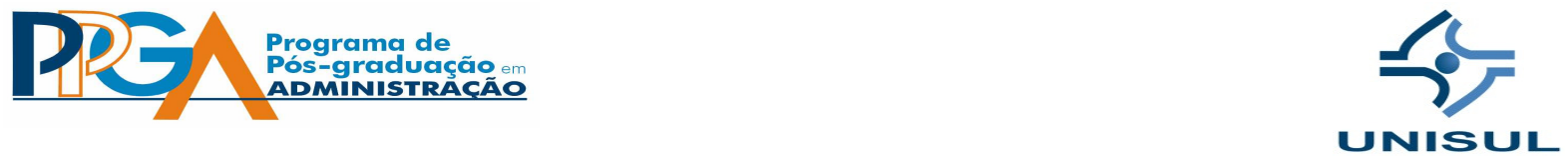

CCopyright 2008 UNISUL-PPGA/Estratégia e Negócios. Todos os direitos reservados. Permitida citação parcial, desde que identificada a fonte. Proibida a reprodução total. Em caso de dúvidas, consulte o editor:

ademar.unisul@gmail.com; (48) 3229-1932. 


\section{RESUMO}

A indústria de autopeças é citada na literatura como um setor industrial envolto em pressões de ordem competitiva de naturezas diversas. Esta indústria enfrenta grandes desafios para controlar seus custos e manter sua rentabilidade, haja vista as pressões sofridas em um mercado complexo e dinâmico. O objetivo da pesquisa é identificar como a gestão de contratos dos projetos de desenvolvimento de novos produtos em uma empresa de autopeças pode contribuir com a geração de valor na empresa. A pesquisa é qualitativa, baseada no método de estudo de caso único em profundidade, por meio das observações realizadas junto às áreas comerciais e de desenvolvimento de produtos de uma empresa líder mundial no fornecimento de Sistemas de Distribuição Elétricos - EDS (componentes elétricos automotivos). A coleta de dados foi feita por entrevista com os executivos e gerentes das áreas estudadas com base na utilização de um questionário semi-estruturado. Os resultados demonstram que em relação à gestão de contratos de novos produtos, a empresa não utiliza de forma estruturada e sistemática conceitos associados à gestão de projetos. Isto faz com que as atividades operacionais não estejam alinhadas aos seus objetivos estratégicos tais como: a) modelar e preparar relatórios padronizados regulares sobre a evolução dos projetos; b) estabelecer um processo formal de aprovação ao final de cada estágio de projeto; c) fortalecer o sistema integrado de mudanças do projeto, pois quando não integrada ou tratada adequadamente pode resultar em destruição do valor da empresa.

Palavras-chave: gestão de Projetos; Ciclo de vida dos Produtos; Gestão de Contratos

\section{INTRODUÇÃO}


O mercado e a indústria automotiva brasileira vêm ganhando destaque no cenário internacional motivado pelos índices de crescimento acima da média global; segundo o Sindicato Nacional da Indústria de Componentes para Veículos Automotores (2010) o crescimento interno da frota circulante brasileira foi de $279 \%$ na última década (2000 a 2009) e de 96\% nos últimos cinco anos (2004 a 2009). Nesse contexto, a constante busca por reduções de custo de aquisições de componentes pelas montadoras tornou a manutenção da rentabilidade dos fornecedores de autopeças, em geral, um exercício de alta complexidade, fato este agravado pelo efetivo poder de negociação das montadoras e pela concorrência acirrada do setor, fatores estes que tornaram as margens dos fornecedores de autopeças extremamente reduzidas; além disso, a dinâmica deste setor da indústria exige uma demanda constante pelo lançamento de novos produtos, voltados ao lançamento de novos modelos de veículos, fato este que torna o cronograma de execução do ciclo de vida dos produtos e seus respectivos projetos de desenvolvimento cada vez mais curtos.

Destaca-se que a dinâmica operacional da indústria de autopeças está associada ao processo de desenvolvimento de novos produtos com base em fatores como prazos de desenvolvimento efetivamente curtos, margens de operação reduzidas, desenvolvimento de projetos de forma simultânea entre montadoras e seus fornecedores diretos e indiretos, elevados investimentos em recursos de engenharia e em novos equipamentos de produção, fatores estes somados às constantes alterações contratuais associadas à cadeia produtiva deste setor. Como fator diferencial neste processo, destaca-se o gerenciamento de projetos associado aos contratos de desenvolvimento de novos produtos como uma tarefa crítica, porém com forte viés positivo de geração de valor, aproximando a execução das tarefas associadas ao desenvolvimento de novos produtos ao planejamento estratégico da empresa em termos de maximização da rentabilidade e manutenção da capacidade competitiva.

Neste contexto, o presente trabalho busca elucidar a seguinte questão de pesquisa: Como a gestão de contratos dos projetos de desenvolvimento de novos 
produtos em uma empresa de autopeças pode contribuir com a geração de valor na empresa? Assim, o objetivo geral foi definido como: identificar como a gestão de contratos dos projetos de desenvolvimento de novos produtos em uma empresa de autopeças pode contribuir a geração de valor na empresa. Adicionalmente foram definidos os seguintes objetivos específicos: (a) Analisar a estrutura da indústria de autopeças, segmento EDS, por meio da identificação das forças competitivas; (b) Analisar o processo de gestão de contratos da empresa; (c) Analisar o processo de gestão de projetos de desenvolvimento de produtos da empresa.

\section{REFERENCIAL TEÓRICO}

\subsection{ANÁLISE ESTRUTURAL E FORÇAS COMPETITIVAS}

A análise estrutural de indústrias foi amplamente estudada por Porter (2004) como ferramenta para a definição do meio ambiente (competitivo) em que atua a empresa. Este meio ambiente é influenciado diretamente por forças competitivas que em conjunto determinam a intensidade da concorrência e também o potencial de lucro desta indústria, medido pelo retorno obtido no longo prazo sobre o capital investido. As cinco forças competitivas classificadas por Porter (2004) estão descritas a seguir sob o ponto de vista de organizações industriais:

- Ameaça de novos entrantes: refere-se a potenciais novas empresas concorrentes que podem ingressar na indústria com investimento e capacidade de desestabilizar o mercado existente;

- Rivalidade entre os concorrentes: corresponde às empresas que já atuam e competem fortemente (concorrem) nesta mesma indústria; 
- Ameaça de produtos substitutos: produtos ou serviços similares que podem desempenhar a mesma função e, portanto substituir aqueles já existentes na indústria;

- Poder dos compradores: o poder de negociação (barganha) que os compradores da indústria (clientes) exercem sobre a empresa;

- Poder dos fornecedores: o poder de negociação (barganha) que fornecedores (provedores de produtos/matéria-prima ou serviços) exercem sobre a empresa e os concorrentes da indústria.

Nesta linha, Hitt, Ireland e Hoskinsson (2008) descrevem o ambiente externo ou geral à indústria e as empresas que o compõem, como influenciadores do ambiente competitivo. Essa dimensão externa à indústria foi por eles segmentada em seis grupos ambientais: demográfico, econômico, sociocultural, global, tecnológico e político/jurídico. Ainda segundo os autores, por exercerem influência na indústria, as empresas devem constantemente monitorar as alterações nesses segmentos ambientais e avaliar quais tem impactos mais relevantes para indústria em que competem e preverem ou reconhecerem ameaças e oportunidades.

Nos últimos anos, algumas metodologias e ferramentas vêm sendo utilizadas para dar suporte às empresas a obterem vantagem competitiva. Neste sentido, a gestão de projetos passa a ganhar destaque, pois cada vez mais as organizações estão gerenciando suas atividades por meio de projetos.

\subsection{GESTÃO DE PROJETOS}

O Project Management Institute (2008) define projeto como um esforço temporário empreendido para criar um produto, serviço ou resultado exclusivo, por isso tem início e término bem definidos. Neste contexto, ainda segundo PMI (2008) o termo "temporário" não está relacionado, necessariamente, a um período de curta 
duração. Independentemente do tamanho ou complexidade, o projeto deve ter os ciclos de iniciação, planejamento, execução, controle e finalização.

Neste contexto, as técnicas da Gestão de Projetos vêm assumindo um papel de destaque como resposta às necessidades de inovação, crescimento e agilidade no meio empresarial. De acordo com Shenhar e Dvir (2010), a participação incremental do setor de operações no resultado global das empresas está em declínio, concomitantemente ao fato da participação da gestão de projetos estar em ascendência. Isto ocorre, sobretudo porque o ciclo de vida dos produtos/serviços está mais curto, os consumidores exigem uma variedade maior de escolhas, e os novos projetos impulsionam o processo de inovação das empresas.

Ainda que os projetos, por definição, estejam baseados em planejamento prévio do conjunto de atividades e entregáveis associados aos respectivos escopos, nota-se que o dinamismo das operações e a velocidade das mudanças notada no desenvolvimento dos cronogramas de execução impingem constantes adaptações ao desenvolvimento dos projetos. Conforme Carvalho e Rabechini (2005), as mudanças ocorridas durante a execução de um projeto podem e devem ser administradas, sendo que em projetos grandes as mudanças são freqüentes e intensas, tornando-se necessário estabelecer um sistema de controle onde o principal dado de entrada é um documento denominado solicitação de mudanças, cujo conteúdo deve refletir, além dos dados das mudanças em si, os impactos que elas podem causar ao projeto e à organização quanto aos seus resultados esperados (normalmente, prazo, custo e qualidade).

Nestes termos, conforme o PMI (2004), em projetos gerenciados sob um contrato, o sistema de controle de mudanças deve também operar alinhado com todas as cláusulas contratuais relevantes. Acerca deste tema, Carvalho e Rabechini (2005), informam que este mesmo sistema deve conter elementos que permitam auxiliar na análise e tomada de decisão de cada uma das mudanças e assim permitir selecionar, 
priorizar as mais relevantes ou ainda suportar os que decidem pelo projeto quanto à aceitação ou rejeição da mudança.

\subsection{PROJETOS DE NOVOS PRODUTOS}

O desenvolvimento de produtos no âmbito industrial foi definido por Rozenfeld et al. (2006) como o conjunto de atividades necessárias para se chegar às especificações de projeto de um produto e de seu processo de produção, para que a manufatura seja capaz de produzi-lo e acompanhá-lo após o seu lançamento, considerando para isso, as necessidades do mercado (clientes e usuários), as restrições tecnológicas e as estratégias competitivas e de produto da empresa. Complementam o processo, a realização de mudanças nas especificações do produto, o plano de descontinuação da produção e a incorporação das lições aprendidas ao longo do desenvolvimento.

O desempenho do projeto de desenvolvimento de produtos (PDP) depende fundamentalmente de um modelo geral para a sua gestão. Este modelo uma vez estruturado propicia um olhar comum de todos envolvidos no processo sobre os objetivos esperados do PDP: o que e como o trabalho deve ser executado, sob quais condições e quais os critérios de decisão devem ser adotados.

Figura 1. Stage-Gate.

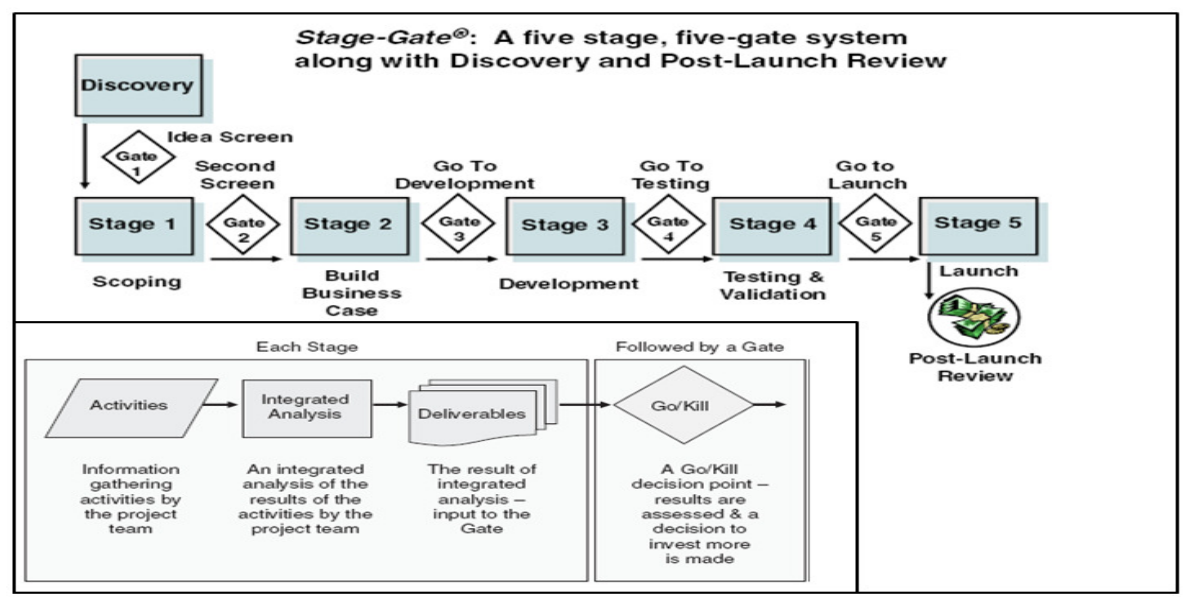

Fonte: Adaptado de Cooper (2008). 
Um dos modelos que adquiriu popularidade como ferramenta voltada à tomada de decisão nos projetos de lançamento de novos produtos foi o Stage-Gate de Robert Cooper. Segundo Cooper (2008), o processo Stage-Gate é composto por cinco stages (estágios) e cinco gates (portais) de decisão, onde a equipe responsável pelo projeto analisa e integra os dados em cada stage, após a passagem pelos gates, conforme figura 1, que consiste de um conjunto de estágios de coleta de informação seguidos por decisões de continuidade/encerramento. Este modelo contribuiu para identificar a importância e mostrar como implementar uma disciplina sistemática de avaliação e transição de fases do PDP, integrada com o processo decisório de planejamento estratégico, garantindo o desempenho e a qualidade do desenvolvimento, considerando também o andamento de todos os projetos e as mudanças no ambiente.

Especificamente para o mercado automotivo, as três grandes montadoras americanas (Chrysler, Ford e General Motors) criaram em 1995 um modelo de desenvolvimento de produto chamado de manual do APQP - Planejamento Avançado da Qualidade do Produto e Plano de Controle, conforme explicitado pela figura 2.

Figura 2. Modelo APQP.

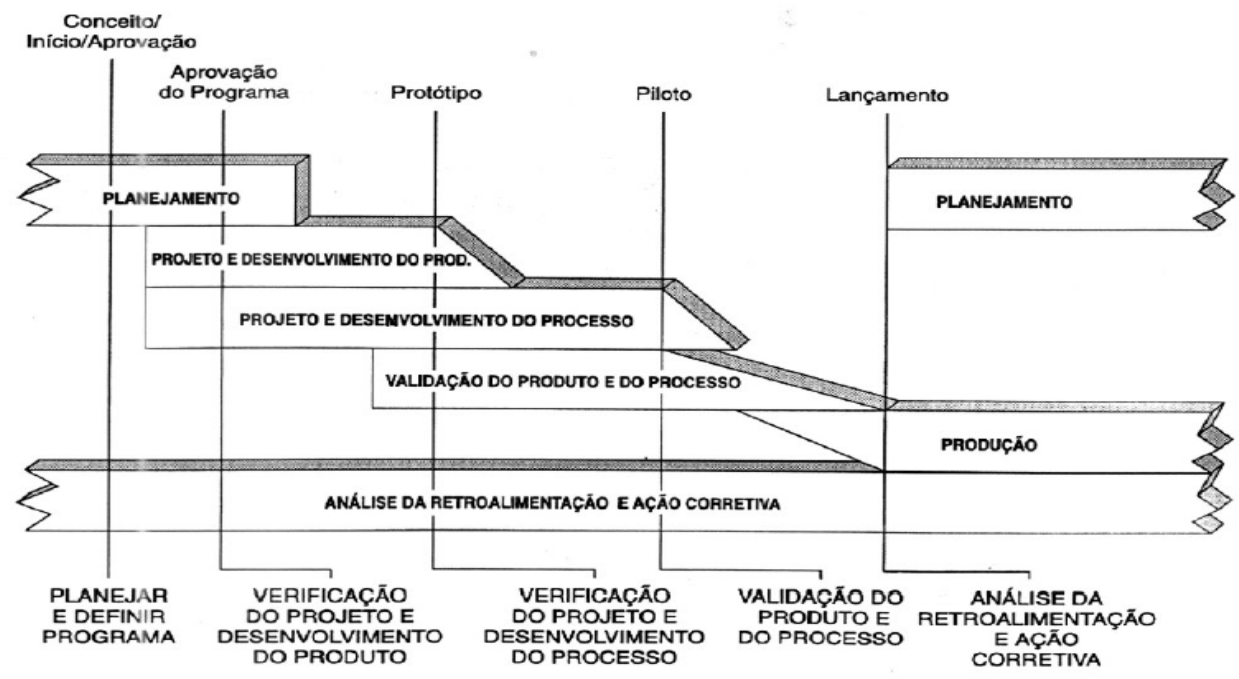

Fonte: Adaptado de Manual do APQP (1995) apud Souza (2006). 
Este modelo também baseado no conceito de engenharia simultânea no qual foi definido um padrão e a maneira esperada que os fornecedores de autopeças desenvolvam seus produtos, sendo todo o processo dividido em cinco fases: planejamento, projeto e desenvolvimento do produto, projeto e desenvolvimento do processo, validação do produto e do processo, produção em massa.

\subsection{O PROCESSO DE GERENCIAMENTO DE MUDANÇAS DE ENGENHARIA}

O gerenciamento de mudanças de engenharia, comumente chamado de ECM (Engineering Change Management), também conhecido por gerenciamento de mudanças de produto (PCM - Product Change Management) é considerado por Rozenfeld et al. (2006) um processo de apoio ao PDP, uma vez que em todas as fases e sub-fases do processo do desenvolvimento podem ocorrer mudanças.

O ECM tem como objetivo controlar todas as mudanças sobre as informações relacionadas à configuração do produto, de modo a garantir a sua integridade permitindo que todas as partes interessadas sempre tenham acesso à última versão. Essas mudanças ocorrem como soluções para os problemas encontrados no desenvolvimento e resultam em diversas alterações no produto.

O modelo de ECM apresentado por Rozenfeld et al. (2006) é dividido em duas etapas principais e subdividido em quatro sub fases, como visto na figura 3. 
Figura 3. Modelo ECM.

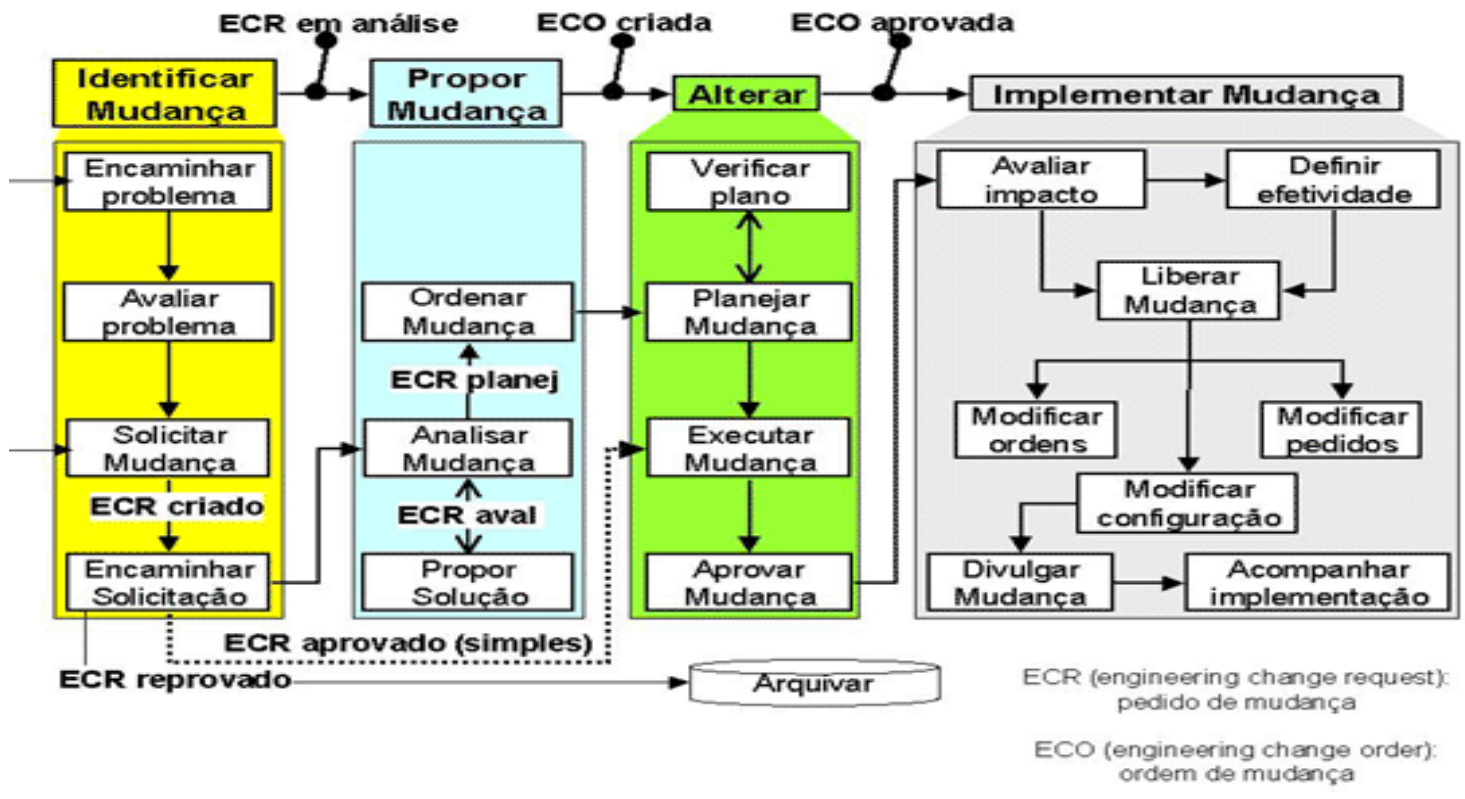

Fonte: ROZENFELD et al. (2006).

A primeira etapa trata da avaliação da mudança e a segunda da implementação da mudança. Cada uma das etapas é suportada por documentações típicas, largamente utilizadas na indústria e são conhecidas dentre outros nomes, por ECR (pedido de mudança) e ECO (ordem de mudança).

\subsection{Contratos}

De acordo com o PMI (2004), os contratos podem ser definidos em três categorias amplas, que dependem dos requisitos impostos pelo cliente, competição do mercado e do grau de risco assumido pelas partes compradoras e vendedoras:

- preço fixo ou valor definido - envolve um preço total fixo para um produto bem definido, tendo como forma mais simples um pedido de compra de um item especificado a ser fornecido até uma data especificada por um tempo especificado. Carvalho e Rabechini (2005) denominaram esta modalidade de contrato de "contrato por empreitada global" ou "EPC - engenharia, aquisição e construção". Nesta modalidade, todo o risco dentro das condições limitantes do contrato é assumido pelo fornecedor; 
- reembolso de custos - envolve o pagamento (reembolso) para o vendedor pelos custos diretos (por exemplo, os salários da equipe que trabalha em tempo integral para o projeto) e indiretos (por exemplo, os salários dos gerentes indiretamente envolvidos no projeto e o custo dos serviços públicos de eletricidade do escritório) acrescidos do lucro. Carvalho e Rabechini (2005) denominaram esta modalidade de contrato de "contrato por administração";

- contrato por tempo e material - é um tipo híbrido de contrato com aspectos de custos reembolsáveis e de preço fixo. Os custos são reembolsáveis por serem modificáveis, podendo ter os seus valores aumentados ou diminuídos, especialmente quando o valor total do acordo e a quantidade exata de itens a serem fornecidos não são definidos pelo comprador no momento do fechamento do contrato. Da mesma forma, podem também ser semelhantes a contratos de preço fixo, quando comprador e pelo vendedor concordam com os valores de alguns itens do contrato (ex: salários de serviços profissionais para uma categoria de recursos específica). Carvalho e Rabechini (2005) denominaram esta modalidade de contrato de "contrato por preço unitário".

Quanto à definição do modelo de contrato a ser utilizado, o PMI (2004) faz uma consideração importante quando existe um potencial de compra futura do produto que está sendo desenvolvido pela equipe do projeto do cliente. Dependendo deste potencial de compra (normalmente atrelado a volume de negócios) é possível que os fornecedores estejam inclinados ou induzidos pelo cliente a cobrar preços menores que os que seriam cobrados sem esse potencial de venda futura.

Conforme o PMI (2004), o processo de administração de contrato deve garantir que o desempenho do vendedor atenda aos requisitos contratuais e que o cliente atue de acordo com os termos do contrato, cabendo ao fornecedor aplicar os processos de gerenciamento de projetos aderente ao contrato firmado. Esses processos de gerenciamento de projetos incluem, entre outros itens, o controle integrado de mudanças, que prevê entre outras ações: 
a) Garantir que as mudanças sejam aprovadas corretamente e notificadas para todas as pessoas que devam ter conhecimento dessas mudanças;

b) Garantir que as condições de pagamento definidas no contrato sejam atendidas e que a compensação ao fornecedor esteja ligada ao seu progresso nas tarefas ou entregas definidas no projeto;

c) Permitir que os contratos possam ser aditados a qualquer momento antes do seu encerramento por acordo mútuo, em conformidade com os termos de controle de mudanças do contrato.

Com relação às solicitações de mudança, o PMI (2004) afirma que todas as alterações devem ser formalizadas por escrito através de documentação pertinente ao contrato (podendo incluir toda as documentações técnicas desenvolvidas, garantias, etc) e aprovadas antes de serem implementadas, podendo incluir essas modificações nos termos e condições do contrato, inclusive em sua declaração de trabalho, no estabelecimento de preços e na descrição dos produtos e serviços a serem fornecidos.

Para isso, o PMI (2004) sugere que deve ser estabelecido um sistema de controle de alteração contratual que defina o processo pelo qual o contrato pode ser modificado, qual a documentação necessária, quais os sistemas de acompanhamento e quais os níveis de aprovação necessários para autorizar mudanças. O sistema de controle de alteração contratual está integrado ao sistema de controle integrado de mudanças conforme descrito em gestão da integração do projeto do referencial teórico desta pesquisa.

O processo de administração de contratos e a implantação de um sistema de controle de alteração contratual podem ser facilitados com o apoio de Tecnologias de Informação e Comunicação (TI), através da centralização dos registros e informações referentes aos contratos que regem os projetos gerenciados pela empresa. Segundo Turban (2009) o uso dessas tecnologias chamadas de Business Intelligence (BI) que transformam dados centralizados em informação, depois em decisões e finalmente em ações fornecem uma vantagem estratégica, pois aumentam 
a eficiência e a eficácia da administração do contrato facilitando o processo de tomada de decisão pelos gerentes de projeto e de contratos.

\section{METODOLOGIA DA PESQUISA}

A pesquisa empírica realizada neste trabalho pode ser classificada como exploratória, qualitativa, indutiva e foi abordada utilizando-se do método de estudo de caso, que tem por objetivo investigar os fenômenos em seu contexto real. Para alcançar estes objetivos, este tipo de método de pesquisa proporciona a coleta estruturada de informações sobre um ou vários objetos de estudo e pode ser aplicado para descrever, explicar, avaliar e explorar fenômenos contemporâneos que não estão sob o controle do investigador. Para Yin $(2005$, p.20) "o estudo de caso permite uma investigação para preservar as características holísticas e significativas dos acontecimentos da vida real - tais como [..] processos organizacionais e administrativos, mudanças ocorridas em regiões urbanas, relações internacionais e a maturação de setores econômicos."

Já para Martins (2006, p.xi), "no campo das ciências sociais aplicadas há fenômenos de elevada complexidade e de difícil quantificação, como, por exemplo, a supervisão das funções administrativas dentro de uma organização, estratégias de uma organização não governamental, políticas governamentais, etc." Nestes casos, segundo Martins (2006), abordagens qualitativas são adequadas, tanto no que diz respeito ao tratamento contextual do fenômeno, quanto no que tange à sua operacionalização. Assim, o tratamento de eventos complexos pressupõe um maior nível de detalhamento das relações, bem como, dos relacionamentos que estabelecem com o meio em que estão inseridos.

Neste contexto, o trabalho de campo de uma pesquisa orientada pela estratégia de um estudo de caso é precedido pela clara exposição do problema de pesquisa e pela formulação de um construto (descrito a seguir) baseado em uma teoria 
preliminar que será validada (ou não) a partir das conclusões da pesquisa (MARTINS, 2006). Para a o desenvolvimento do trabalho, foi realizado um estudo caso único através de pesquisa exploratória baseada na coleta de dados primários por meio de questionário individual semi-estruturado por pautas, considerando-se a triangulação de dados necessária neste tipo de estudo, foi realizada ainda pesquisa complementar por meio da análise de documentos cedidos temporariamente pela empresa estudada, e por entrevista a perfis profissionais em ocasiões e localidades distintas e pelo acesso às informações da empresa por meio da internet (site da empresa e demais informações veiculadas pela imprensa).

\subsection{COLETA DE DADOS}

A empresa pesquisada é uma multinacional atuante na indústria de autopeças e líder mundial no segmento de "Sistemas de Distribuição Elétricos" (EDS) e sub-componentes associados ao EDS, responsável pelo abastecimento de cerca de $30 \%$ da produção global de veículos em 2008.

Com nove instalações no Brasil em quatro estados, a empresa conta atualmente com cerca de 4000 funcionários, dos quais 70\% estão alocados em atividades diretas à produção, $17 \%$ em atividades de suporte à produção, 3\% em atividades administrativas incluindo suprimentos, logística, marketing e vendas e $10 \%$ em atividades de engenharia. As atividades de engenharia estão divididas em desenvolvimento de novos produtos, engenharia de produção, gerenciamento de projetos, qualidade e laboratório.

A coleta de dados primários desta pesquisa foi realizada com a utilização de questões semi-estruturadas dirigidas aos executivos e gerentes das áreas de engenharia, projetos e vendas, as quais se constituíram nas unidades de análise do estudo. Desta forma, foram convidados profissionais da empresa que na ocasião estavam diretamente envolvidos nos processos de gestão de contratos e projetos de 
desenvolvimento de produtos, todos com experiência mínima de dez anos na indústria e no segmento de EDS, capacitados para responder individualmente às questões propostas na forma de entrevista, com as respostas autorizadas para serem gravadas com a finalidade de evitar perda de tempo e de informações. Cada entrevista durou aproximadamente 90 minutos. Posteriormente as entrevistas foram transcritas para o formato de texto para que uma análise de conteúdo pudesse ser realizada com maior propriedade.

\subsection{CONSTRUTO DA PESQUISA}

A partir da revisão bibliográfica efetuada, visando alcançar o escopo do estudo e obter a resposta à questão da pesquisa, elaborou-se um construto de pesquisa compatível com os objetivos do estudo. O construto foi propositalmente subdividido em clusters relacionados aos principais marcos teóricos conforme orientam Miles e Huberman apud Maccari (2008), a fim de facilitar a prospecção de informações e facilitar o processo de análise dos resultados. As respostas dos gestores da empresa ao questionário não estruturado foram organizadas conforme apresentado no Quadro 1 a seguir:.

\section{Quadro 1: Construto da Pesquisa}

\begin{tabular}{|c|c|c|}
\hline Objetivos da Pesquisa & Cluster & Variáveis \\
\hline $\begin{array}{l}\text { Analisar a estrutura da } \\
\text { indústria de autopeças, } \\
\text { segmento EDS, através da }\end{array}$ & $\begin{array}{l}\text { Análise das forças } \\
\text { competitivas de Porter }\end{array}$ & $\begin{array}{l}\text { Clientes } \\
\text { Fornecedores } \\
\text { Concorrentes } \\
\text { Novos entrantes } \\
\text { Produtos substitutos }\end{array}$ \\
\hline competitivas & $\begin{array}{l}\text { Análise do ambiente } \\
\text { externo ou geral }\end{array}$ & Ambiente externo \\
\hline
\end{tabular}




\begin{tabular}{|c|c|c|}
\hline Analisar o processo de gestão & Gestão de contratos & $\begin{array}{l}\text { Estrutura } \\
\text { Modelos } \\
\text { Integração }\end{array}$ \\
\hline \multirow[b]{2}{*}{$\begin{array}{l}\text { Analisar o processo de projetos } \\
\text { de desenvolvimento de } \\
\text { produtos da empresa; }\end{array}$} & $\begin{array}{l}\text { Alinhamento } \\
\text { estratégico }\end{array}$ & Estratégia \\
\hline & $\begin{array}{ll}\text { Gestão } & \text { do } \\
\text { Desenvolvimento } & \text { de } \\
\text { produtos } & \end{array}$ & $\begin{array}{l}\text { Estrutura } \\
\text { Modelo } \\
\text { ECM }\end{array}$ \\
\hline $\begin{array}{l}\text { Descrever as ações a serem } \\
\text { consideradas para que gestão } \\
\text { de contratos dos projetos de } \\
\text { desenvolvimento } \\
\text { fornecimento da empresa } \\
\text { atenda aos seus objetivos } \\
\text { estratégicos }\end{array}$ & (todos os Clusteres) & (todas as variáveis) \\
\hline
\end{tabular}

Fonte: adaptado de Maccari (2008).

Adicionalmente, foram seguidos rigorosamente todos os procedimentos indicados para a condução de estudos de caso, conforme referenciados por Yin (2005). Os nomes das empresas foram mantidos em sigilo a pedido da maioria dos entrevistados.

\section{ANÁLISE DOS RESULTADOS}

Como exposto, a análise das respostas foi classificada em seis clusters distintos, seguindo a seqüência dos objetivos específicos estabelecidos para este trabalho. O primeiro permite averiguar a análise das forças competitivas existentes dentro da indústria de autopeças, segmento EDS. O segundo faz análise do ambiente externo a essa indústria. O terceiro analisa a gestão de contratos da empresa com relação a sua estrutura, modelos aplicados e integração com o processo de gestão do 
PDP. O quarto verifica o alinhamento dos processos de gestão de contratos e do PDP com os objetivos estratégicos da empresa. O quinto analisa a gestão do PDP com relação a sua estrutura, modelo de gestão de projetos adotado e o processo de gerenciamento de mudanças de engenharia. E por último no sexto, são apresentadas na parte referente à conclusão deste trabalho, as ações a serem consideradas para responder ao objetivo geral desta pesquisa.

\subsection{ANÁLISE DA INDÚSTRIA DE AUTOPEÇAS - SEGMENTO EDS}

\section{Cluster - Forças Competitivas}

$\mathrm{Na}$ análise deste cluster, foram identificadas as características relacionadas às cinco forças competitivas da empresa, descritas a seguir:

a) fornecedores (matéria-prima): $70 \%$ do volume de compras está concentrado em seis grandes fornecedoras dos principais sub-componentes do EDS (conectores plásticos, contatos metálicos e cabos). A maioria dos seus insumos de produção são commodities (cobre, resinas plásticas, etc.), portanto, sujeitos às flutuações da economia nacional e internacional;

b) novos entrantes: basicamente constituídos por concorrentes asiáticos (chineses e coreanos) que ensaiam se estabelecer no Mercosul seguindo seus principais clientes (montadoras chinesas e coreanas) que também pretendem fortalecer a produção local de veículos no Mercosul;

c) substitutos: foi considerada pelos executivos a importação direta pelas montadoras, o EDS produzido em outras localidades com custos de produção mais competitivos que o Mercosul. Outro substituto potencial pode vir da mudança tecnológica no EDS como os sistemas sem-fio (wireless, Bluetooth, etc.). No momento, nenhuma destas tecnologias foi validada para substituir com confiabilidade o EDS convencional; 
d) clientes (montadoras): poucos clientes, empresas globais estabelecidas no Mercosul com alto poder de barganha devido aos grandes volumes de produção;

e) concorrência atual: o mercado é dominado por nove grandes empresas, todas multinacionais, sendo $70 \%$ do volume de produção do Mercosul concentrado em apenas três concorrentes. O líder de mercado regional responde por $40 \%$ do volume fornecido, produz seus próprios sub-componentes e também abastece os seus concorrentes na qualidade de fornecedor. Todas têm as montadoras como seu maior cliente, uma vez que o mercado de reposição é irrelevante no segmento EDS o que aumenta dependência desta indústria e conseqüentemente a rivalidade e a competitividade do setor.

\section{Cluster - O Ambiente Externo}

$\mathrm{Na}$ análise do ambiente geral e externo ao segmento EDS, foram considerados como mais relevantes os agentes descritos a seguir:

a) Economia: por ter sua estrutura de matéria-prima diretamente atrelada à variação de commodities, flutuações econômicas e demanda internacional afetam diretamente os custos de produção. Por ter sua demanda derivada da demanda das montadoras, efeitos na economia (taxa de juros, acesso do consumidor ao crédito e inflação) também afetam diretamente os resultados do segmento;

b) Sindicatos: como o segmento depende de mão-de-obra intensiva para produzir seus produtos, uma vez que 70 a $80 \%$ de sua força de trabalho estão direta ou indiretamente ligadas à produção, a pressão sindical por aumentos salariais acima da inflação ou concessão de benefícios, tem forte efeito nos custos de produção;

c) Governo (federal ou estadual): legislação trabalhista tem influência direta nos custos de mão-de-obra, assim como incentivos fiscais como redução de IPI para automóveis produz efeitos diretos na indústria de autopeças devido à demanda derivada das montadoras. 
GESTÃO DE PROJETOS APLICADA AOS CONTRATOS DE NOVOS PRODUTOS NO SETOR DE AUTOPEÇAS

Rudolf Friedrich Fromm - Emerson Antonio Maccari - Cláudia Terezinha Kniess - Cesar Augusto Biancolino - Giovane da Costa

A análise da indústria através da adaptação do diagrama das cinco forças de PORTER (2004), considerando os dados coletados sobre as forças competitivas e o ambiente externo, contribui para melhor ilustrar o ambiente competitivo que o segmento EDS no Brasil está inserido (figura 4).

Figura 4 - Ambiente competitivo do segmento EDS no Brasil.

Sindicatos:

- Dissidios trabalhistas (6 a $7 \%$ a.a)

- Pressão por transferencia de linhas

Novos entrantes:

Concorrentes asiáticos (chineses e

coreanos) que pretendem se estabelecer

no país.

\section{Fornecedores:}

$70 \%$ concentrado em 3 grandes empresas

Grandes escalas de produção;

Conhecimento da estrutura de custos dos

insumos que consomem

- Dificil substituição

- Insumos dos fornecedores são commodities

(cobre e resinas plasticas), sujeitos as

flutuações da economia

\section{Concorrencia atual:}

9 empresas multinacionais

$70 \%$ do mercado concentrado em 3

empresas

- Mercado de reposição irrelevante,

aumentando a rivalidade pelos clientes

montadoras;

Grande dependencia apenas desta

industria (automobilística)

Substitutos:

Sistemas Bluetooth

- Importação direta

\section{Governo federal e estadual:}

- Leis trabalhistas (encargos, regulação)

- Incentivos fiscais (IPI, ICMS estadual)

- Incentivos a industrialização (infraestrutura)

Fonte: adaptado de PORTER, Michael (2004)

\section{Clientes (Montadoras):}

Alto poder de barganha;

- Grandes escalas de produção;

Conhecimento da estrutura de custos dos insumos que consomem

Substituição relativamente rápida ( 3 a 6

meses)

Economia:

Inflação

- demanda internacional afteam as

commodities (Cobre, resinas plasticas)

- Demanda derivada das montadoras

- Taxa de juros e facilidade de crédito

\subsection{ANÁLISE DO PROCESSO DE GESTÃO DE CONTRATOS}

\section{Cluster - Gestão de Contratos}

As respostas fornecidas pelos executivos da empresa permitiram identificar aspectos do modelo de gestão de contratos adotado nas tratativas comerciais com 
seus clientes, revelando características de sua estrutura hierárquica, responsabilidades e sistemas de apoio e integração com outras áreas da empresa, como descrito a seguir:

Estrutura: a área comercial da empresa responde pela gestão de contratos comerciais com os clientes e tem entre outras atribuições, a responsabilidade primária de contato comercial com os clientes suportando às RFQ's e solicitações de alterações contratuais. Também é responsável por consolidar os custos estimados e precificar as ofertas de desenvolvimento e fornecimento do produto. Deve realizar as análises de viabilidade financeira dos projetos (retorno de investimento, pay-back, etc), monitorar e reportar a evolução contratual ao longo do ciclo de vida do produto. Os gestores da área indicaram não existir uma estrutura robusta de apoio à gestão de contratos, baseada em plataforma tecnológicas de BI integrados ao ERP da empresa, o que dificulta a atividade de gestão de contratos, pois não permite o acesso centralizado e rápido aos históricos de negociações anteriores tais como descontos concedidos, além de consolidação de volumes de fornecimento e faturamento. Nesse contexto, a responsabilidade pela organização das informações para a tomada de decisões comerciais e estratégicas da empresa, sai de uma esfera sistêmica e recai sobre o individuo responsável por atender aos clientes (gestor de contas). Com relação aos indicadores, existem informações padronizadas que medem o desempenho durante a fase de pré-desenvolvimento para a obtenção de novos negócios (taxa de sucesso e viabilidade financeira) e também no monitoramento do desempenho financeiro no início de produção e pós-desenvolvimento (faturamento mensal, custo de produção, margem bruta, etc). Não foram identificados indicadores padronizados em todos os clientes, que controlem o desempenho da evolução contratual durante a fase de desenvolvimento do produto.

Modelo: as respostas indicaram que todos os clientes seguem um padrão referente às situações de compras, conforme o estágio do ciclo de vida que o produto se encontra. Na fase que antecede o desenvolvimento do produto, durante a seleção dos fornecedores, os clientes se enquadram na situação de "nova compra" quando 
fazem a pré-qualificação de fornecedores, abrem licitações de compras por meio de consultas chamadas de solicitações de cotação de novos produtos (RFQ). A RFQ contempla o escopo do desenvolvimento do produto, as condições de fornecimento, e um pacote de especificações de produto. A modalidade de contrato predominante é a de preço fixo, quando são fixados os valores para o desenvolvimento do produto, como também o preço de venda do produto. Posteriormente são coletadas as ofertas das empresas participantes da licitação. Nesta fase o ciclo de vendas está em aberto. Nos exemplos citados pelos executivos ficou evidente a existência de vários agentes internos ao cliente com poder de influência na decisão de fornecimento (engenharia, qualidade, logística, finanças, compras entre outros), constatado pela aprovação consensual de um comitê multifuncional liderado pela área de compras que avalia todas as ofertas. A escolha do fornecedor ocorre após várias rodadas de negociação, quando é definido um contrato base. Uma vez nomeado o fornecedor do produto, os clientes se enquadram na situação de "recompra modificada". Para o segmento de EDS, essa situação é muito recorrente durante o desenvolvimento do veículo, quando o volume de alterações de engenharia solicitadas pelos clientes, ocorrem com maior freqüência. A "recompra modificada" cobre as alterações contratuais e de especificações de produto sobre o contrato base da licitação original. Nesta situação, os agentes influenciadores de decisão são bastante reduzidos e limitam-se a avaliar as variações financeiras sobre as condições do escopo original definido no contrato base. Após o lançamento do veículo no mercado (pós-desenvolvimento), a "recompra modificada" é menos freqüente uma vez que o produto atinge a sua maturidade e as alterações são mais raras. Neste estágio, os clientes se enquadram na situação de "recompra simples", no qual os pedidos e programação de fornecimento são colocados automaticamente através de protocolos EDI.

Integração: as respostas indicaram não existir um modelo interno robusto de controle integrado de mudanças que coordene e controle as ações de gestão de contratos com as ações de controle de alterações de engenharia por solicitações dos 
clientes. As respostas indicaram o controle ser direcionado muito mais pelas ações e solicitações dos clientes, do que por um processo interno que garanta respostas homogêneas alinhadas aos objetivos da empresa, independente do cliente ou projeto.

\section{4ำ Cluster - Alinhamento Estratégico}

Nessa etapa, o questionário buscou extrair informações dos gestores da empresa sobre o alinhamento estratégico das atividades de gestão de contratos e de gestão de projetos de desenvolvimento de produtos, como também identificar o envolvimento da alta administração nestes processos.

Quando a empresa se propõe a participar de uma nova licitação, já é previsto um direcionamento estratégico com metas bem definidas a serem atingidas. Essas metas podem ser de aumento de participação de mercado, garantir alinhamento estratégico com outras unidades da empresa em outros países (uniformidade de fornecimento), evitar a entrada ou perda de participação em determinado negócio ou mesmo preencher a capacidade ociosa de suas unidades produtivas. A rentabilidade mínima esperada para determinado produto é o principal indicador de alinhamento estratégico do negócio.

Durante uma nova licitação, na maioria dos casos, a alta administração da empresa participa formalmente da análise de viabilidade financeira do negócio antes que qualquer oferta seja enviada ao cliente e também nas rodadas seguintes de negociação. Nesta etapa são estabelecidos os parâmetros financeiros, de rentabilidade mínima, de desempenho e produtividade esperados para o projeto, que nortearão os preços e descontos que podem ser ofertados pelos gestores de contas.

Em alguns casos, foram identificadas dificuldades para a busca de histórico e registros sobre os parâmetros financeiros, rentabilidade esperada e condições comerciais de descontos autorizados para determinadas ofertas. A falta de um sistema formal ou integrado de BI foi apontada como a principal causa desta dificuldade. 
Após a nomeação como fornecedora de determinado projeto e produto, não foi identificada a participação formal ou sistemática da alta administração da empresa em revisões regulares dos projetos em desenvolvimento, para verificar se existe convergência entre os objetivos estratégicos e a evolução natural do projeto. A participação da alta administração, quando ocorre, é feita de maneira não regular apenas em projetos considerados de maior relevância estratégica.

Os projetos voltam todos a ser monitorados novamente, somente após o inicio de produção com base nos relatórios financeiros provenientes das áreas de operações da empresa.

\subsection{ANÁLISE DO PROCESSO DE GESTÃO DE PROJETOS DE DESENVOLVIMENTO DE PRODUTOS}

\section{5o Cluster - Gestão de PDP}

Nessa etapa do questionário, os executivos da empresa forneceram respostas que permitiram identificar aspectos do modelo e estrutura de gestão de projetos, do desenvolvimento de produtos e do sistema de controle de alterações de engenharia $(E C M)$ da empresa revelando características de suas responsabilidades, dinâmica de trabalho, sistemas de apoio e integração com outras áreas da empresa. Descreve-se a síntese das respostas a seguir:

a) Modelo: a respostas dos gestores indicaram não haver um modelo unificado do processo de desenvolvimento de produto (PDP) para toda a empresa. A priori, os projetos são desenvolvidos seguindo a sistemática solicitada pelos próprios clientes. Basicamente, todos os sistemas são baseados no conceito de engenharia simultânea, tendo como referência o APQP, sendo o seguimento deste obrigatório para as montadoras americanas (Chrysler, Ford e GM). Derivações deste modelo são utilizadas por outras montadoras européias tais como ANPQP ou VDA. As montadoras 
japonesas adotam outros processos também baseados no conceito de engenharia simultânea. Embora todas as metodologias de clientes utilizadas para desenvolver produtos sejam conceitualmente muito similares, as terminologias e documentações de projeto empregadas, assim como os padrões de qualidade e entrega de produtos diferem bastante de um cliente para outro. Essas diferenças foram apontadas como um entrave para todas as partes interessadas (stakeholders) que não sejam exclusivamente dedicadas a determinado cliente ou projeto, para um entendimento comum sobre o status dos projetos, dificultando o processo de tomada de decisões. Por não haver um processo formal interno de aprovação dos estágios de desenvolvimento do produto e processo produtivo, ou mesmo indicadores internos de desempenho específicos para esse processo, os estágios são considerados aprovados pela empresa, através dos gates de aprovação determinados pelos clientes. Um exemplo citado foi o Processo de Aprovação da Peça de Produção (PPAP) previsto no processo de APQP, que aprova a qualidade dos produtos a serem fornecidos antes do inicio de produção em massa (SOP), através da verificação da linha de produção e diversos documentos que devem ser preparados atestando a qualidade e robustez do produto e do processo produtivo.

b) Estrutura: a empresa adota para a gestão de projetos, estruturas matriciais fracas, na qual os gerentes de projetos e as equipes de projeto respondem para gerentes funcionais. As equipes de projetos são compostas por representantes das áreas de vendas (gestor de contas), engenharia de desenvolvimento produto, engenharia de processos, qualidade, controladoria e suprimentos (compras e logística). Normalmente, os gerentes de projeto pertencem à organização de engenharia de desenvolvimento de produto ou comercial e tem a função de interface principal dos projetos com os clientes. Os principais indicadores de desempenho do processo referem-se ao atendimento das datas chaves dos entregáveis do projeto, conforme gates de aprovação estabelecidos pelos clientes mencionados 
anteriormente no modelo de gestão de projetos. Os executivos não souberam identificar indicadores de desempenho associados ao impacto de alterações de engenharia com relação aos objetivos estratégicos da empresa.

c) ECM: a engenharia de desenvolvimento de produtos adota um modelo padrão de controle de alterações de engenharia para todos os projetos, baseado no conceito de ECR's e ECO's, não suportado por plataformas tecnológicas através de sistemas de PDM/PLM ou GED. O processamento da ECR define a viabilidade técnica de determinada proposta de alteração de produto, normalmente gerada para solucionar problemas de natureza técnica, de desempenho do produto ou mesmo para redução de custo do produto ou processo produtivo. A maior dificuldade citada neste processo ocorre quando as solicitações de alteração são urgentes e existe a necessidade por parte do cliente, da incorporação imediata da mudança no produto. Normalmente esses pedidos ocorrem por parte da área de engenharia do cliente e quando não coordenadas com a área comercial do cliente (compras), podem gerar um desalinhamento nas prioridades das áreas internas da empresa e os impactos de custos podem não ser totalmente capturados. Uma vez aprovada a ECR, a engenharia de desenvolvimento de produto gera uma ECO e a alteração é incorporada no produto. Foi confirmada a grande incidência de emissão de ECO's durante a fase de desenvolvimento. As alterações de escopo do projeto que contemplam mudanças não intrínsecas ao escopo do produto, normalmente são relacionadas às condições gerais de fornecimento, tais como local de entrega, freqüência logística, condições de pagamento, volumes contratuais e prazos e quantidades de entregas de amostras e protótipos. Elas ocorrem com maior freqüência na fase mais inicial do desenvolvimento, ou ainda no pré-desenvolvimento durante as negociações da etapa de nomeação de fornecedor. Uma vez definida fonte, as alterações de escopo de projeto são mais raras e predominam as alterações de engenharia relacionadas ao escopo do produto. Uma vez lançado o produto, as mudanças são mais raras e quando ocorrem, são para sanar problemas técnicos que não foram identificados durante as 
etapas de validação do desenvolvimento do produto ou por iniciativas de redução de custos por parte dos clientes.

\section{CONCLUSÕES}

Observando-se todo o modelo/construto e as respostas dadas pelos executivos quanto às práticas que a empresa vem adotando no momento, é possível concluir que a empresa apesar de já adotar algumas boas práticas, ainda que não sistematizadas, que não consegue comparar e verificar lacunas nos processos existentes.

A comparação dos resultados obtidos em projetos distintos com características similares indica que o seu maior ou menor alinhamento em relação aos seus objetivos estratégicos estabelecidos no início dos projetos, permite concluir que a gestão de contratos com os clientes quando não integrada adequadamente à gestão dos projetos de desenvolvimento do produto, ou não tratada com importância estratégica pela alta administração, pode resultar em destruição do valor da empresa.

Desta maneira, a questão da pesquisa pode ser respondida com as seguintes ações a serem consideradas para que gestão de contratos dos projetos de desenvolvimento e fornecimento de produtos da empresa atenda aos seus objetivos estratégicos:

a) Os objetivos estratégicos de cada projeto devem ser amplamente divulgados pela alta administração da empresa para a equipe responsável pelo projeto;

b) Os objetivos estratégicos devem ser registrados adequadamente e facilmente acessados pelas partes interessadas a qualquer momento durante o ciclo de vida do desenvolvimento do produto; 
c) Preparação de relatórios padronizados regulares sobre a evolução dos projetos para alta administração durante o desenvolvimento do produto, usando como referência o escopo base do projeto (Project Charter);

d) Criação de indicadores que permitam monitorar e corrigir a evolução dos níveis de preço e rentabilidade esperada durante o desenvolvimento do produto, usando como referência as bases financeiras no qual o projeto foi aceito (análise inicial de rentabilidade);

e) Criação de um modelo unificado de PDP, independente do processo solicitado pelos clientes, que permita o entendimento claro dos diferentes projetos e auxiliem na tomada de decisão por parte da alta administração;

f) Estabelecimento de um processo formal de aprovação de gates por parte da alta administração ao final de cada estágio de projeto;

g) Estabelecimento dos critérios de aprovação dos gates;

h) Fortalecimento do sistema integrado de mudanças do projeto, para que não seja influenciado pela dinâmica do que é e como é solicitado pelos clientes.

i) Estabelecimento de um plano de implantação de BI integrado aos sistemas de ERP da empresa.

j) Estabelecimento de um plano de implantação de gestão eletrônica de documento (GED) integrado aos sistemas de ERP da empresa.

Em relação ao primeiro objetivo específico - Analisar a estrutura da indústria de autopeças, segmento EDS, por meio da identificação das forças competitivas - as principais conclusões deste estudo foram a confirmação da alta competitividade da indústria resultando em margens de rentabilidade média do setor bastante reduzidas.

Já para o segundo objetivo específico - Analisar o processo de gestão de contratos da empresa - considerando o porte da empresa e a complexidade de sua carteira de projetos e clientes, as respostas indicam que a não centralização e 
automatização referente à organização das informações para a tomada de decisões comerciais e estratégicas da empresa, em plataformas tecnológicas do tipo $\mathrm{BI}$ integrados ao ERP, aumenta o risco de falhas no processo (não atendimento dos objetivos estratégicos). Isto devido à maior transferência da responsabilidade uma esfera sistêmica para o individuo responsável por atender aos clientes (gestor de contas). Dada essa constatação, é possível concluir que parte da inconsistência de resultados obtidos nos diversos clientes-chaves (montadoras) é influenciada em muitos casos, apenas pelo desempenho da interface comercial do fornecedor com a montadora.

No que concerne ao terceiro objetivo específico - Analisar o processo de projetos de desenvolvimento de produtos da empresa - os dados obtidos permitem afirmar que na empresa já existe certa maturidade, cultura e estrutura instaladas de gestão de projetos e de gestão de alterações de engenharia, o que facilita a adoção de um modelo unificado de PDP. A falta desta unificação dá indícios da dificuldade de acompanhamento por parte da alta administração da empresa com relação a evolução dos projetos durante o desenvolvimento dos produtos.

A criação de um modelo unificado de PDP, somado a um sistema automatizado de gestão de documentos referentes ao ECM, devem facilitar o acompanhamento regular por parte da diretoria da empresa do andamento de todos os projetos, e a evolução do resultado de sua administração contratual, permitindo observar e prever com maior precisão qual será o resultado financeiro quando o projeto estiver concluído e as vendas em massa iniciarem.

\section{PROJECT MANAGEMENT APPLIED TO CONTRACTS OF NEW PRODUCTS IN THE AUTOMOTIVE SECTOR}

\section{ABSTRACT}


The auto parts industry is cited in the literature as an industry shrouded in competitive pressures of various kinds. This industry faces big challenges to control costs and maintain profitability, given the pressures in a complex and dynamic market. The research aims to identify how the contract management of development projects of new products in an auto parts company can contribute to create value in the company. The research is qualitative, based in unique case study method, by means of observations carried out with the areas of trade and product development in leading global supplier of Electrical Distribution System- EDS (automotive electrical components). Data collection was done by interviewing executives and managers of the areas studied based on the use of a semi-structured questionnaire. The results show that in relation to contract management of new products, the company doesn't use in a structured and systematic concepts associated with project management. This makes the operational activities are not in line with its strategic objectives such as: a) standard model and prepare regular reports on the progress of projects; b) establish a formal approval process by the end of each stage of the project; c) strengthen the integrated design changes, because when not part of or treated properly can result in destruction of firm value.

Keywords: Project Management; Product life cycle; Contract Management

\section{REFERÊNCIAS}

Carvalho, M. M., Rabechini, R, Jr. (2005). Construindo competências em gerenciamento de projetos: teoria e casos. São Paulo: Editora Atlas.

Cooper, R. G. (2008). Perspective: The Stage-Gate Idea-to-Launch Process-Update, What's New, and NexGen Systems. Product Innovation Management.

Hitt, M. A., Ireland, R. D, Hoskinsson, R. E. (2008). Administração Estratégica. São Paulo: Thomson Learning. 
Maccari, E. A. (2008). Contribuições à Gestão dos Programas de Pós-Graduação Stricto Sensu em Administração no Brasil com Base nos Sistemas de Avaliação NorteAmericano e Brasileiro. Tese de Doutorado, Universidade de São Paulo, São Paulo, SP, Brasil.

Martins, G. A., (2006). Estudo de Caso, Uma Estratégia de Pesquisa. São Paulo: Atlas.

Project Management Institute.(2004). PMBoK - Um Guia do Conjunto de Conhecimentos em Gerenciamento de Projetos [Manual] 3a Edição.

Project Management Institute.(2008). Organizational Project Management Maturity Model. Maryland. EUA.

Porter, M. E. (2004). Estratégia Competitiva: técnicas para análise da indústria e da concorrência. Rio de Janeiro: Elsevier, $2^{a} \underline{a}$ ed.

Rozenfeld, H, Forcellini, F. A., Amaral, D.C.,De Toledo, J. C., Da Silva, S. L., Alliprandini, D.H., Scalice, R. K. (2006). Gestão de desenvolvimento de produtos. São Paulo: Saraiva.

Shenhar, A. J.; Dvir, D. (2010). Reinventando Gerenciamento de Projetos. São Paulo: Makron.Books.

Sindicato Nacional da Indústria de Componentes para Veículos Automotores,(2009). Análise da variação de custo e preço 2005/2008 segmento montadora. Assessoria Econômica. Disponível em:

http://www.sindipecas.org.br/paginas_NETCDM/modelo_pagina_generico .asp?ID_CANAL=514. Acesso em 15/06/2010.

Souza, V. P. (2006). Gestão de projetos de desenvolvimento de autopeças.

Dissertação de Mestrado. Escola Politécnica da Universidade de São Paulo, São Paulo, SP, Brasil.

Turban, E. (2009) Business Intelligence: um enfoque gerencial para a inteligência do negócio. Porto Alegre: Bookman.

Yin, R. K. (2005). Estudo de Caso - Planejamento e Métodos. 3 ed. Porto Alegre: Bookman. 